Report Title:

A STUDY OF MULTISTAGEMULTIFUNCTION COLUMN FOR FINE PARTICLE SEPARATION

\title{
Report Type:
}

Principal Author(s): Dr. Shiao-Hung Chiang

$$
\text { Dof/PC/94217--79 }
$$

Report Issue Date: 10/20/1996

DOE Award No.: DE- PG22 -94PC94217

Submitting

Organization(s)

Name \& Address
Dr. Shiao-Hung Chiang

Chemical and Petroleum Engineering Department

University of Pittsburgh

Pittsburgh, PA 15261 


\section{DISCLAIMER}

This report was prepared as an account of work sponsored by an agency of the United States Government. Neither the United States Government nor any agency thereof, nor any of their employees, make any warranty, express or implied, or assumes any legal liability or responsibility for the accuracy, completeness, or usefulness of any information, apparatus, product, or process disclosed, or represents that its use would not infringe privately owned rights. Reference herein to any specific commercial product, process, or service by trade name, trademark, manufacturer, or otherwise does not necessarily constitute or imply its endorsement, recommendation, or favoring by the United States Government or any agency thereof. The views and opinions of authors expressed herein do not necessarily state or reflect those of the United States Government or any agency thereof. 


\section{DISCLAIMIER}

Portions of this document may be illegible in electronic image products. Images are produced from the best available original document. 


\section{DISCLAIMER}

This report was prepared as an account of work sponsored by an agency of the United States Government. Neither the United States Government nor any agency thereof, nor any of their employees, makes any warranty, express or implied, or assumes any legal liability or responsibility for the accuracy, completeness, or usefulness of any information, apparatus, product, or process disclosed, or represents that its use would not infringe privately owned rights. Reference herein to any specific commercial product, process, or service by trade name, trademark, manufacturer, or otherwise does not necessarily constitute or imply its endorsement, recommendation, or favoring by the United States Government or any agency thereof. The views and opinions of authors expressed herein do not necessarily state or reflect those of the United States Government or any agency thereof. 


\begin{abstract}
EXECUTIVE SUMMARY
Wastewater treatment tests program was initiated in this quarter to verify the multifunction features of the multistage column. A new column was constructed for the oily water cleanup. Non-disperse infrared spectroscopy (NDIR) technique was selected for oil content analysis.
\end{abstract}




\section{Table of Contents}

Page

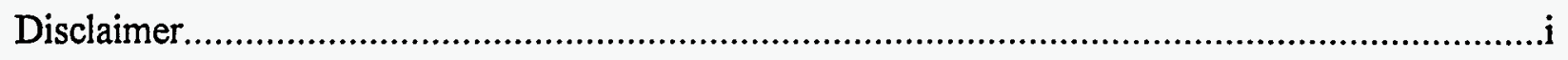

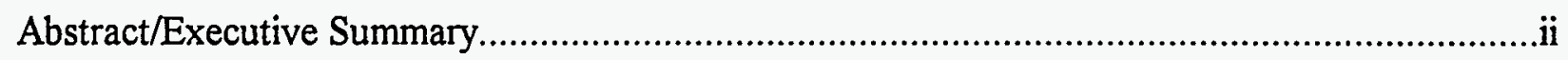

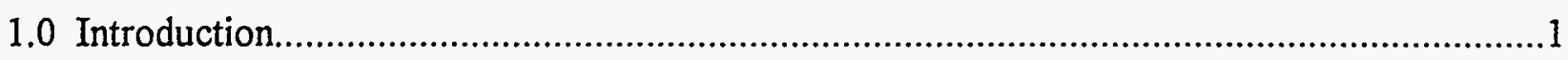

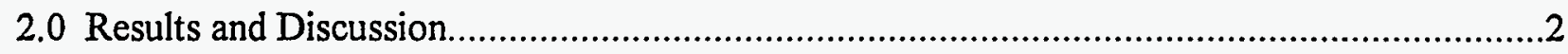

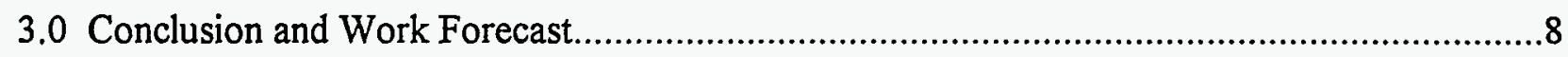

4.0 Reference. 


\subsection{INTRODUCTION}

The overall objective of the research program is to explore the potential application of a new invention involving a multistage column equipped with vortex-inducing contactors (hereafter referred to as the multistage column) for fine coal cleaning process. The research work will identify the design parameters and their effects on the performance of the separation process. The results of this study will provide an engineering basis for further development of this technology in coal cleaning and in the general areas of fluid/particle separation.

In the last quarter, we performed data analysis of the bubble sizes using a model based on the unified proportionality equation ${ }^{[1-3]}$. In this quarter, we continue to carry out the wastewater treatment tests program, initiated in the last quarter, to demonstrate the multifunction features of the multistage column. Table 1.1, the project schedule, shows work accomplished to date.

Table 1.1 Project Schedule

\begin{tabular}{|c|c|c|c|c|c|c|c|c|c|c|c|c|c|}
\hline \multirow{2}{*}{ Tasks } & \multicolumn{3}{|c|}{1994} & \multicolumn{3}{|c|}{1995} & \multicolumn{3}{|c|}{1996} & \multicolumn{3}{|c|}{1997} & \\
\hline & 7 & 9 & 12 & 3 & 6 & 9 & 12 & 3 & 6 & 9 & 12 & 3 & 6 \\
\hline 1. Project Planning & 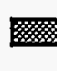 & & & & & & & & & & & & \\
\hline 2. Equipment & & & & 7. & & & & & & 傦 & & & \\
\hline 3. Hydrodynamic Tests & & & & r & & & & & & & & & \\
\hline 4. Separation Tests & & & & & & & & & & 翌 & & & \\
\hline 5. Conventional Column Tests & & & & & & & & & & & & & \\
\hline 6. Data Analysis & & & & & & & & & & 覴 & & & \\
\hline 7. Reports & & $\square$ & $\square$ & $\square$ & 图 & $\square$ & $\square$ & $\square$ & 圂 & $\square$ & $\square$ & $\square$ & \\
\hline
\end{tabular}

Notes: $\quad$ Quarterly Technical Progress Report; $\mathbf{0}$ Annual Report; 2 Final Report. 


\subsection{RESULTS AND DISCUSSION}

\subsection{Task 1: Project Planning}

This task was completed in September $1994^{[4]}$.

\subsection{Task 2: Equipment Design and Construction}

\subsubsection{Objective}

Currently, the objective is to modify an existing multistage column system in our lab for general use in wastewater treatment. This unit includes a multistage flotation column, a gas supply system and associated ancillaries.

\subsubsection{Current Status of Task 2}

During this reporting period, the modification and construction have been completed for the oily wastewater treatment tests to demonstrate the multifunction features of the multistage column. Shake-down tests in this newer version of multistage column have been carried out. Both liquid and gas flowmeters have been re-calibrated. An oil content analyzer OCMA-220 has been purchased and set up. The OCMA-220 is designed to measure organic hydrocarbon contamination in fresh or salt water samples. The non-dispersive infrared (NDIR) technique used in this analyzer closely approximates several EPA standards in which oil is extracted with a solvent, which is then analyzed by infrared spectroscopy ${ }^{[S]}$. The analyzer has been calibrated with the standard samples provided by the manufactures.

\subsection{Task 3: Hydrodynamic Tests}

The objective of this task is to pursue a basic understanding of the hydrodynamic behavior and to characterize the flow and mixing conditions in the multistage separation column. This task was completed in December $1995^{[6-8]}$ for the previous version of the agitated column for solid-solid 
separations. The hydrodynamic tests for the newly constructed column for liquid-liquid separation is to be performed in the next quarter.

\subsection{Task 4: Separation Tests}

To demonstrate the multifunction features of the multistage column, the separation tests in Task 4 have focused on the investigation of wastewater treatment since April 1996. The goal of this phase of the study is to examine the potential application of the column to the general areas of fluid/particle separation and evaluate the effectiveness of the multistage column in these processes. The detailed description of the technical progress for this quarter is presented below.

\subsubsection{Objective and Scope}

The objective of this phase of our study is to explore the potential application of the multistage column for water treatment. The experimental work focused on identifying the effect of operating parameters on the column performance used as wastewater treatment device and demonstrating its multifunctional features in the removal of contaminants (such as dispersed oil) from wastewater.

\subsubsection{Experimental Setup and Procedure}

The experiments is to be performed in a three-stage non-agitated flotation column. The column configuration is depicted in Figure 2.4.1. It consists of a plexiglass column which is $0.1 \mathrm{~m}$ in diameter and $2.95 \mathrm{~m}$ in height. In the column, three set of concentric draft-tubes and baffle cones (see Figure 2.4.2) were installed to create multiple loop flow patterns. The diameter ratio of draft tube to column is 0.75 . The length of each draft tube is approximately $0.62 \mathrm{~m}$. 


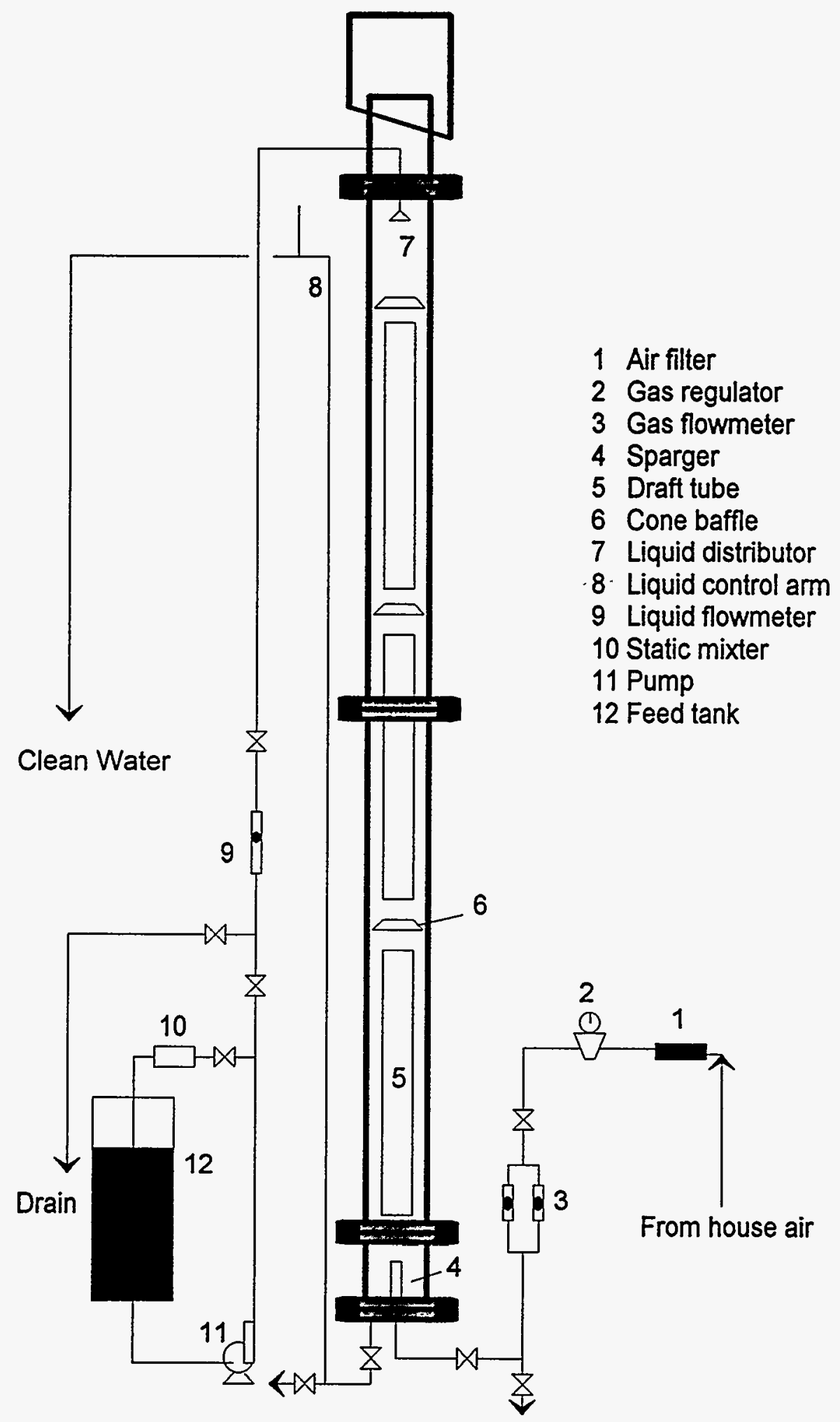

Figure 2.4.1 Multistage Flotation Column for Waste Water Treatment 

A simulated wastewater sample is prepared by adding a pre-determined amount of a light mineral oil (LMO) with a density of $874 \mathrm{~kg} / \mathrm{m}^{3}$ at $25^{\circ} \mathrm{C}$. The oil/water mixture is emulsified in a 50 gallon feed tank by pumping through a static mixer for about 60 minutes. Based on our previous experience, the oil-water emulsion prepared in this manner is very stable and no coalescence of oil droplets is expected. The initial oil concentration in water is set to be $500 \mathrm{mg} / \mathrm{L}$. 2-Ethyl-1hexanol (2-EH) is used as frother. The superficial gas velocity varies over a range up to $4.0 \mathrm{~cm} / \mathrm{s}$. Table 2.4.1 lists the operating conditions used in the study.

Table 2.4.1 Operating Conditions

\begin{tabular}{|l|c|}
\hline \multicolumn{1}{|c|}{ Parameters } & Conditions \\
\hline Superficial gas velocity $(\mathrm{V}), 10^{-2} \mathrm{~m} / \mathrm{s}$ & $0.5-4.0$ \\
\hline Feed rate, liter $/ \mathrm{min}$ & $1-5$ \\
\hline Reagent dosage (C), $\mathrm{mg} / \mathrm{L}$ & $0.0-20.0$ \\
\hline Temperature, $^{\circ} \mathrm{C}$ & 25 \\
\hline
\end{tabular}

The oily water is fed to the top of column and a constant water level is maintained. Gas bubbles are generated by a vertical perforated metal sparger (mean pore size of $10 \mu \mathrm{m}$ ), which is located at the bottom of the column. Gas bubbles pass through each contactor upward in contact with the down-flowing oily wastewater simulant stream. The gas-lift action causes a circulation (or loop flow) of fluids around each draft tube. The treated water leaves the bottom of the column via the clean water discharge line, while the oil-laden foam overflows into the foam discharge tank. Clean water samples are collected and analyzed for oil content using an OCMA-220 oil content analyzer. 


\subsubsection{Oily Water Treatment Test Program}

Tests will be performed in the multistage column to study the effects of hydrodynamic behavior, resulted from various operating conditions and geometry, on the oily water clean-up performance. The oil removal efficiency, $\eta$, is the performance criterion and defined as

$$
\eta=\frac{C_{o}-C_{f}}{C_{o}} \times 100 \%
$$

where $\mathrm{C}_{0}$ and $\mathrm{C}_{\mathrm{f}}$ are the initial and final oil concentrations, respectively.

The experimental test program will be initiated next quarter.

\subsection{Task 5: Conventional Column Tests}

In this quarter, no additional experiment was carried out in the conventional column.

\subsection{Task 6: Data Analysis}

In the past several quarters, data for the gas holdup, bubble size and specific interfacial area in the agitated column ${ }^{[9]}$ were analyzed in terms of three key operating parameters: V, N and C. Data analysis for the non-agitated column will be presented after the new round of separation tests and hydrodynamic tests are conducted. 


\subsection{CONCLUSION AND WORK FORECAST}

In this quarter, efforts were mainly devoted to the construction and modification of the new multistage column for liquid - liquid separations. Shake-down of the equipment was performed. The emulsified oil cleanup was chosen as the model system and oil removal efficiency was defined as the criterion of process performance.

In the next quarter, preliminary oily wastewater separation tests will be carried out as the part of work under Task 4 to study the application of the multistage column to the other separation processes and to demonstrate its multi-function capability. Work will include the following:

(1) The effect of operating conditions on the oil removal efficiency;

(2) Preliminary study on oil flotation kinetics;

(2) Continue to prepare a data basis for engineering design and economic analysis of the multistage flotation system. 


\subsection{REFERENCES}

1. "A Study of Multistage/Multifunction Column for Fine Particle Separation", Quarterly Technical Progress Report, (April 1 - June 30, 1996), Chemical \& Petroleum Engineering Department, University of Pittsburgh, Submitted to U.S. Department of Energy, PETC, July 20, 1996.

2. Lai, R. W., "How to Obtain More Information Out of Flotation Kinetics Data," Trans. AIME Vol. 272, 1982, p. 1989.

3. Lai, R. W., M. W. Lai, J. A. Musser, and P. C. Rehmet, The Modern Proportionality Law for Science, Medicine, and Engineering Applications, The Toshi Company, Pittsburgh, PA, 1995, p. 384.

4. "A Study of Multistage/Multifunction Column for Fine Particle Separation", Quarterly Technical Progress Report, (July 8 - September 30, 1994), Chemical \& Petroleum Engineering Department, University of Pittsburgh, Submitted to U.S. Department of Energy, PETC, January 20, 1995.

5. The OCMA-220 Instruction Manual, Irvine, California, September 1994, p. 1-1.

6. "A Study of Multistage/Multifunction Column for Fine Particle Separation", Quarterly Technical Progress Report, (April 1, 1995 - June 30, 1995), Chemical \& Petroleum Engineering Department, University of Pittsburgh, Submitted to U.S. Department of Energy, PETC, July 20, 1995.

7. "A Study of Multistage/Multifunction Column for Fine Particle Separation", Quarterly Technical Progress Report, (July 1, 1995 - September 30, 1995), Chemical \& Petroleum 
Engineering Department, University of Pittsburgh, Submitted to U.S. Department of Energy, PETC, October 20, 1995.

8. "A Study of Multistage/Multifunction Column for Fine Particle Separation", Quarterly Technical Progress Report, (October 1, 1995 - December 31, 1995), Chemical \& Petroleum Engineering Department, University of Pittsburgh, Submitted to U.S. Department of Energy, PETC, January 20, 1996.

9. “A Study of Multistage/Multifunction Column for Fine Particle Separation", Annual Technical Progress Report, (July 8, 1995 - July 7, 1996), Chemical \& Petroleum Engineering Department, University of Pittsburgh, Submitted to U.S. Department of Energy, PETC, July 26, 1996. 